\title{
Sarambipá: esparramos, resistência e rearticulação Guarani na recuperação do Tekoha Guasu extinto pela Itaipu Binacional ${ }^{1}$
}

\author{
Sarambipá: dispersión, resistencia y reordenamiento guaraní en la \\ recuperación de Tekoha Guasu extinguido por Itaipu Binacional \\ Sarambipá: Guarani dispersal, resistance and rearticulation in the \\ recovery of Tekoha Guasu extinguished by Itaipu Binacional
}

\author{
Clovis Antonio Brighenti² \\ Osmarina de Oliveira ${ }^{3}$
}

\begin{abstract}
Resumo
No dia 13 de outubro de 1982 as comportas da hidrelétrica de Itaipu Binacional foram fechadas. Esse ato não acabou apenas com o maior salto por volume d'água no mundo, conhecido como Sete Quedas, mas também com o território Guarani nas margens do Rio Paraná ou o Paraná Rembe, cujas terras eram as que restavam aos Guarani após o processo violento de colonização e, segundo Bonomo, esse seria o território de origem dessa população. Concomitante a construção e instalação da referida obra identificamos dois momentos distintos: o sarambi ou esparramo, durante a construção do lago; posteriormente iniciam processo de reagrupamento e reorganização das relações sociopolíticas. Analisaremos esse conflito e os mecanismos de resistência na perspectiva da histórica do povo Guarani seus processos de lutas históricos e contemporâneos no campo político e jurídico. Tendo figurado como protagonista em diferentes contextos e conflitos, como a aliança Guaraníticojesuíta e a consequente guerra travada contra os impérios ibéricos, a Guerra da Tríplice Aliança, a criação do reservatório de Itaipu etc., este povo viu seu território ser transformar em mercadoria. Na contemporaneidade, os Guarani têm construído diferentes mecanismos de enfrentamento às adversidades, como a ressignificação de sua cosmologia e reorganização sociocultural para assumir uma nova postura diante das adversidades, além da reinterpretação e ressignificação das relações com a terra e o território. Nos contínuos processos de construção e transformação de suas concepções territoriais surge um novo elemento, a retomada de terras enquanto instrumento de resistência. Os processos de retomadas incidem nos territórios alagados por Itaipu Binacional, não em sua composição física, mas na dimensão simbólica, já que essas terras não mais existem. Reformulam seu discurso a fim de reafirmar o direito à terra e para isso mobilizam diferentes mecanismos, como a produção de documentos e a elaboração de novos discursos.
\end{abstract}

Palavras-Chave: Conflitos; Território; Guarani; Itaipu; Resistências.

\section{Resumen}

Nel día 13 de octubre de 1982, se cerraron las compuertas de la represa hidroeléctrica Itaipu Binacional. Este acto no solo puso fin al mayor salto por volumen de agua en el mundo, conocido como Sete Quedas, sino también con el territorio guaraní a orillas del río Paraná o el Paraná Rembe, cuyas tierras fueron las que

\footnotetext{
1 Artigo apresentado no I Congresso Internacional Online de Estudos sobre Culturas, na modalidade online, 2019.

${ }^{2}$ Doutor em História; Professor do Instituto Latino Americano de Arte Cultura e História da Universidade Federal da Integração Latino Americana (UNILA); Foz do Iguaçu, Paraná, Brasil; clovisbrighenti@ hotmail.com.

3 Graduação em Geografia; Mestranda pelo PPG/IELA/Unila. Foz do Iguaçu, Paraná, Brasil. osmarina66@gmail.com;
} 
quedaron a los guaraníes después del violento proceso. Según Bonomo, este sería el territorio original de esta población. Concomitante con la construcción e instalación de este trabajo, identificamos dos momentos distintos: el sarambi o dispersión durante la construcción del lago; posteriormente comienzan el proceso de reagrupación y reorganización de las relaciones sociopolíticas. Analizaremos este conflicto y los mecanismos de resistencia en la perspectiva histórica del pueblo guaraní, sus procesos de luchas históricas y contemporáneas en el ámbito político y jurídico. Habiendo figurado como protagonista en diferentes contextos y conflictos, como la alianza guaranito-jesuita y la consiguiente guerra librada por los imperios ibéricos, la Guerra de la Triple Alianza, la creación del embalse de Itaipú, etc., estas personas vieron su territorio convertirse en una mercancía. En los tiempos contemporáneos, los guaraníes han construido diferentes mecanismos para hacer frente a la adversidad, como la resignificación de su cosmología y la reorganización sociocultural para asumir una nueva postura frente a la adversidad, además de la reinterpretación y resignificación de las relaciones con la tierra y el territorio. En los procesos continuos de construcción y transformación de sus concepciones territoriales, surge un nuevo elemento, la recuperación de las tierras como instrumento de resistencia. Los procesos de retoma se centran en los territorios inundados por Itaipu Binacional, no en su composición física, sino en la dimensión simbólica, ya que estas tierras ya no existen. Reformulan su discurso para reafirmar el derecho a la tierra y para ello movilizan diferentes mecanismos, como la producción de documentos y la elaboración de nuevos discursos.

Palabras claves: Conflictos; Territorio; Guaraní, Itaipu; Resistencias.

\begin{abstract}
On october 13, 1982, the floodgates of the Itaipu Binacional hydroelectric dam were closed. This act not only ended the biggest jump by volume of water in the world, known as Seven Falls, but also with the Guarani territory on the banks of the Paraná River or the Paraná Rembe, whose lands were the Guarani that remained after the violent process. According to Bonomo, this would be the original territory of this population. Concomitant with the construction and installation of this work, we identified two distinct moments: the sarambi or spread during the construction of the lake; subsequently they begin the process of regrouping and reorganizing sociopolitical relations. We will analyze this conflict and the mechanisms of resistance in the historical perspective of the Guarani people, their processes of historical and contemporary struggles in the political and legal field. Having figured as a protagonist in different contexts and conflicts, such as the Guaranito-Jesuit alliance and the consequent war waged by the Iberian empires, the Triple Alliance War, the creation of the Itaipu reservoir, etc., these people saw their territory become a commodity. In contemporary times, the Guarani have built different mechanisms to cope with adversity, such as the resignification of their cosmology and sociocultural reorganization to assume a new posture in the face of adversity, in addition to the reinterpretation and resignification of relations with land and territory. In the continuous processes of construction and transformation of their territorial conceptions, a new element emerges, the retaking of lands as an instrument of resistance. The retaking processes focus on the territories flooded by Itaipu Binacional, not in their physical composition, but in the symbolic dimension, since these lands no longer exist. They reformulate their discourse in order to reaffirm the right to land and for that they mobilize different mechanisms, such as the production of documents and the elaboration of new discourses.
\end{abstract}

Keywords: Conflicts; Territory; Guarani; Itaipu; Resistors.

\title{
1. Introdução
}

O período em análise coincide com o regime militar, cujo golpe ocorreu em 1964 e seu término, com a posse do governo civil se deu em 1985. Tanto a Itaipu Binacional como a Funai eram presididos por generais. Nos anos de maior conflitos e relações com os Guarani a Funai era presidida pelo General Ismarth Araújo de Oliveira ${ }^{4}$, e, em 1979, já com a Usina

\footnotetext{
4 "General da Reserva, antes de ser nomeado presidente havia sido superintendente da FUNAI. Na sua posse, o Ministro do Interior, Rangel Reis, anunciou "a política de integração em ritmo acelerado", o que viria a desembocar no projeto de emancipação dos índios, contra o qual ele se opôs publicamente. Mas incrementa os
} 
praticamente concluída e em meios a dois mandatos tampão, assume a presidência da Funai outro General, Carlos Nobre da Veiga ${ }^{5}$. Nobre da Veiga ocupara um posto vinculado a grandes projetos de desenvolvimento e, atuava diretamente no Serviço Nacional de Informação (SNI). A Itaipu Binacional estava sendo presidida por outro general José Costa Cavalcanti, notoriamente ligado a criação do Ato Institucional nº 5 (AI-5), imposto em 1968 e a Guarda Indígena (GRIN) ${ }^{6}$, pertencente a chamada "linha dura" da Ditadura Civil-Militar. O Incra, como demonstram vários estudos, também seguia uma linha tutelada pela ideologia da segurança nacional. Os três órgãos citados tinham sua Assessoria de Segurança e Informação (ASI) vinculadas diretamente ao SNI. Soma-se a isto o regime tenso na região da "tríplice fronteira" em meio a um projeto de "segurança nacional", a Operação Condor, dentre outros fatores. (MAZZAROLLO, 2003).

As margens do rio Paraná foram os últimos Tekoha kuéra (aldeias) que restaram aos Guarani. Ali era o lugar do refúgio depois de toda terra arrasada no oeste paranaense pela colonização com sua prática de agricultura intensiva a partir da década de 1950. Nas margens do rio Paraná ainda havia mata, local de refúgio dos Guarani. Os dados arqueológicos pesquisados por Igor Chmyz na década de 1970 e as pesquisas históricos comprovam a presença dessa população na região. Em nossas pesquisas de campo identificamos ao menos 19 Tekoha Kuéra que ficaram total ou parcialmente submersos pelo Lago. Dos 19, apenas o Tekoha Ocoy Jacutinga foi admitido pelos órgãos públicos, por ser o local onde os Guarani conseguiram resistir por mais tempo, por ser também o local que "perturbou” a Itaipu até o fechamento das comportas. Ela nunca foi demarcada oficialmente, porém, de acordo com o Art. 25 da Lei 6001/1973 a terra indígena precede e independe da demarcação. O caso Ocoy Jacutinga é também um importante elemento que nos permite compreender o todo, ou seja, como os Guarani foram informados, como Itaipu os considerou, qual a atitude da Funai e do

chamados "projetos de desenvolvimento comunitário", dentro de uma política de "espíritos desarmados" com antropólogos, indigenistas e missionários. Na sua gestão, aumentam substancialmente as demarcações de Terras Indígenas”. (Disponível em: http://pib.socioambiental.org/pt/c/politicas-indigenistas/orgao-indigenistaoficial/galeria-dos-presidentes-da-funai. Acesso em: 16/10/2015).

5 João Carlos Nobre da Veiga (presidente da Funai entre nov. 1979 a out. 1981. "Assume o cargo falando em "disciplina" e demitindo 39 indigenistas e antropólogos, porque haviam encaminhado carta ao Ministro do Interior com críticas a política da FUNAI. Incrementa o projeto de emancipação compulsória, criando os famosos "critérios de indianidade" e declarando que 'o índio estará emancipado em cinco gerações'; mas recua [devido a pressão do movimento indígena] e não encaminha o processo ao Ministério do Interior (MINTER). Reestrutura a FUNAI para fortalecer as unidades regionais. Numa reunião da SUDAM, afirma que 'há reservas demais'. A 15/12/1980, sai uma Portaria Interministerial (MINTER/ Min. das Minas e Energia) facilitando a exploração mineral em terras indígenas por empresas estatais. Com base no parecer do Conselho Indigenista da FUNAI, o Ministro do Interior, Mario Andreazza, proíbe Mario Juruna, liderança indígena do povo Xavante, de participar do Tribunal Russel, na Holanda." (Idem).

6 Folha de São Paulo, Laura Capriglione disponível em:http://www1.folha.uol.com.br/ilustrissima/2012/11/1182605-como-a-ditadura-ensinou-tecnicas-de-torturaaguarda-rural-indigena.shtml. Acesso em julho de 2014. 
Incra e as "soluções" encontradas. Os demais Tekoha kuéra não aparecem nos registros do órgão indigenista e sequer foram considerados.

Esse conjunto de tekoha kuéra alagados, formavam uma unidade sociológica definida como Tekoha Guasu, ou seja, um conjunto de comunidades articuladas social, política e economicamente por redes de sociabilidade, parentescos consanguíneo e afins. Porém, essas relações não representavam/representam centralização de poder, ao contrário, eram/são comunidades cuja mobilidade no Tekoha Guasu é mais intensa que com outras comunidades. Na contemporaneidade podemos identificar dois Tekoha Guasu na margem esquerda do rio Paraná, um ao sul do município de Santa Helena e outro ao norte. A memória dos Guarani contemporâneos sobre as relações interétnicas a partir dos anos 1950 indica que já estavam constituídos dessa maneira, porém é relevante considerar as dimensões da violência a que estavam submetidos.

\section{Para uma história Guarani}

Pesquisas científicas com a população Guarani demandam um conhecimento prévio da cultural, história, cosmologia e das dinâmicas atuais e históricas (tradicional) de mobilidade. Há uma dinâmica específica sobre as fronteiras que, ligadas a mobilidade territorial, é singular por estar em contexto bastante específico. É na dinâmica da fronteira que se evidencia com maior nitidez o significado das mesmas para esse conjunto de comunidades que se articulam por redes linguísticas e territoriais desafiando o universo colonial.

Os registros da memória Guarani através das pesquisas participativas são fundamentais para trazer a luz novas versões da história a partir dos sujeitos envolvidos no processo.

Partiremos dos pressupostos básicos da teoria e metodologia da história indígena, na perspectiva de iniciativas plurais entre diferentes áreas do conhecimento, especialmente na relação entre antropologia e história, relação que nos últimos anos tem fundamentado inúmeras pesquisas empíricas em diferentes tempos e espaços na América Latina nos quais os indígenas são enfocados com sujeitos do processo (ALMEIDA, 2012, p.151). O diálogo entre história e antropologia implica ir além do domínio metodológico, "os etno-historiadores devem dominar ainda a arte de usar essas duas abordagens de maneira integrada" (TRIGGER, apud ALMEIDA, 2012, p.158). Cardoso (2012) também concorda que a "nova história cultural" está com um pé em cada mundo e tem na antropologia a "interlocutora privilegiada". 
A abordagem que propomos dialoga com as ciências ambientais e sociais, mais especificamente com a história ambiental e a geografia. O diálogo entre as várias áreas do conhecimento não se resume a uma necessidade "legal", mas, constitui-se como um dos pressupostos teóricos metodológicos da história indígena, que em seu percurso está se consolidando como um método que congrega, além da antropologia e geografia, áreas como arqueologia e linguística (EREMITES DE OLIVEIRA, 2003).

A pesquisa em história indígena caminha para a construção de novos marcos referenciais em sua abordagem. Apesar de incipiente, os pressupostos teóricos devem partir de outras temporalidades, diferentemente da abordagem clássica da história. Afinal os indígenas não ingressaram na história apenas no século XV durante o período colonial, a arqueologia é um importante instrumento para demonstrar a longevidade da presença dessas populações no continente (CARNEIRO DA CUNHA, 1992), nesse sentido ampliam-se os universos de fontes para além da produção escrita, sejam de indígenas ou não indígena, deslocando-se para a cultura material e imaterial, dos conhecimentos e saberes transmitidos na oralidade. As relações estabelecidas com indígenas na atualidade não podem ser pautadas pelos conceitos de transitórios ou mesclados sugerindo que esses seriam menos indígenas que as gerações passadas, mas na relação de sujeitos históricos de seu tempo, agindo a partir das condicionantes temporais e tradicionais.

Ao trabalhar com a história indígena no tempo presente é importante considerar a dimensão da memória. Maurice Halbwachs (2006, p.86) nos ensina que "ao lado de uma história escrita há uma história viva que se perpetua ou se renova através dos tempos". Halbwachs discorre sobre a memória coletiva, apontando para a dimensão social da mesma, contextualizada nas vivencias particulares. Alessandro Portelli também traz significa contribuição a compreensão dos processos de registro da memória, porém na dimensão individual: "A memória é um processo individual que ocorre no meio social dinâmico, valendo-se de instrumentos socialmente criados e compartilhados" (PORTELLI, 1997, p.116).

O registro da memória passa necessariamente pela oralidade. Para o registro da oralidade trabalharemos a partir das orientações de Meihy, que nos adverte que "não é apenas quando não existem documentos que a História Oral acontece. Ela é vital também para produzir outras versões das histórias elaboradas com documentos cartoriais, consagrados e oficiais".

\section{Do sarambi a reorganização}


Na língua Guarani sarambipá é esparramar-se (sarambi = esparramo). Ele é usado para designar o movimento migratório Guarani que ocorre desde muito antes da chegada dos jurua kuéra, porém, com o processo de colonização e, fundamentalmente com a construção da Itaipu Binacional o conceito foi empregado de maneira negativa, para explicar a desterritorialização. Soavinski (2019), já registrou essa narrativa em sua pesquisa:

\begin{abstract}
Como sinaliza o cenário durante o período de colonização intensiva do oeste paranaense era, invariavelmente, o de espoliação dos índios: de seus corpos e de suas terras. Os relatos do tempo do sarambi, do esparramo, são muitos; os mais velhos lembram-se vivamente dos anos que sucederam à chegada dos colonos. Tendo se dispersado rumo aos estados e municípios vizinhos e também ao Paraguai e à Argentina, muitos encontraram empregos, na maioria das vezes de temporada, em fazendas. Trabalhavam, pois, para os próprios colonos que ocasionaram a perda de suas terras e, na região. (SOAVINSKI, 2019, p. 53).
\end{abstract}

No caso da desterritorialização provocada pela formação do lago da usina de Itaipu Binacional, o conceito é empregado em seu sentido mais extremo de negatividade. $\mathrm{O}$ fato dos Guarani desconhecerem o que significava o represamento de um rio como o Paraná e a extinção do território, gerou um esparramo total. O único local, na margem esquerda do rio, que ficou ocupado até a véspera do fechamento das comportas foi o Ocoy/Jacutinga, localizado no atual município de São Miguel do Iguaçu, entre a foz do rio Ocoy e do riacho Jacutinga.

Na memória Guarani, o Tekoha Ocoy Jacutinga teria sido reservado pelos militares: "Os militares falaram: 'aqui é de vocês, ninguém entra'" (BRANT DE CARVALHO, 2005, p.03). Essa atitude do exército foi resultado da participação Guarani como mão de obra na abertura da estrada de Guarapuava a Foz (ROCHA, 1991, p.25). Claramente está demonstrada a exploração da mão de obra Guarani, porque de acordo com a Lei de Terras de 1850, os indígenas tinham direito sobre as terras que ocupavam, ou seja, o Exército teria pago com a terra que já era Guarani.

Sobre a terra ocupada pelos Guarani no Ocoy Jacutinga, o Incra criou um projeto de assentamento de camponeses, desapropriando toda a terra, através do Decreto Federal № 69.412/1971 e o denominou de PIC Ocoy, com 12.500 ha e iniciou a expulsão dos Guarani do local. Joao Centurião, líder Guarani, observa que a ação do Incra foi extremamente violenta. "Apareceu assim, bota fogo na casa. (...) E aí não se não quis sair, aí vinha e tem que botar fogo (...) não dizia porque tinha que sair, não falou nada não. Era só Incra, não tinha polícia" (CENTURION, 1990). Narcisa Tacua Catu de Almeida confirma as informações de Centurião:

Em 1972 o Incra chega aqui, expulsando a gente da terra, eles assustavam a gente, ameaçava, mandava embora, botando fogo nas casas, queimando nossa plantação, 
atirava nossas coisas na estrada, expulsando a gente daqui... ameaçava dar tiro na perna, quem não queria subir no caminhão. (CATU DE ALMEIDA, 2005).

A prática do Incra era atear fogo nas casas para expulsar as famílias Guarani do local como o propósito de usar a terra por eles ocupada para assentar camponeses que ocupavam o Parque Nacional do Iguaçu. Posteriormente, com a Itaipu em construção a queima das casas era para evitar que outras pessoas se apropriassem do imóvel ou no caso dos Guarani para evitar seu retorno, já que muitos haviam fugido do local. Jussara Rezende, que acompanhou parte do processo por uma organização indigenista, testemunhou a queima das casas pelo Incra, afirmando que "no caso dos colonos, eles já não estavam mais nas suas casas. Suas casas eram incendiadas pelo Incra inclusive para evitar que fossem ocupadas novamente" (REZENDE, 2015).

Com a criação da Itaipu Binacional, pelo Art. III do Tratado celebrado entre a República Federativa do Brasil e a República do Paraguai, em 26 de abril de 1973, o projeto do Incra sofre mudanças. Dos 12,5 mil hectares inicialmente tomados dos Guarani pelo Incra e reservados para assentamento dos camponeses, 8.322 ha ficaram submersos restando apenas 4.168 ha. O Ocoy Jacutinga estava localizado justamente na parte que ficaria submersa. Brant de Carvalho (2004), em seu laudo antropológico demonstra que toda área utilizada pelo Incra para o assentamento de agricultores era de ocupação Guarani - devendo, por exigência legal da época, ter sido demarcada pela Funai em favor destes.

No novo contexto, do alagamento das terras por Itaipu Binacional, foram gestados acordos entre os órgãos federais (Incra e Funai com a Itaipu) a fim de justificar a expulsão dos indígenas da margem do rio. A notícia gerou novo esparramo das famílias Guarani que ainda ocupavam a terra.

A partir de entrevistas concedidas pelos Guarani em diferentes contextos e de diferentes gerações é possível reconstituir a violência com que foram tratados: "Então ele [pai do entrevistado, Severo Bogado] falou que na época de 1960 quanto entrou lá, ele entrou tinha vida boa, tinha peixe, tinha água, tinha tudo (...), que ele não tinha problema nenhum antes que a Incra entrou lá”. (BOGADO, 1990).

Pedro Alves diz que a comunidade Guarani não foi informada da obra, sabiam pelas conversas com vizinhos: “A gente sabia quando o vizinho não-índio falava! [...] Então nós que estamos na beira do rio Paraná temos que sair [...]. Foi assim que a gente ficou sabendo?!" (ALVES, 2013). 
A notícia de Itaipu gerou dispersão dos Guarani, denominado por eles como Sarambi. Faustino Centurião, residente na época na tekoha Passo Kue, relata a mudança deste local para o Paraguai:

(...) porque não tinha jeito para cá. Mesmo que Jacutinga, quando vem também, tá no perigo. Então cada aldeia encheu de perigo. Então teve que passar pro Paraguai. Por isso que Itaipu escreveu que era paraguaio. Mas de nação, natural mesmo é daqui. Tudo que veio de lá era tudo nascido no Paraná mesmo, no Brasil. (CENTURIÃO, 1990).

Semelhante depoimento foi prestado por Damásio Martinez demonstrando como os Guarani fugiram da violência do Incra e da Itaipu:

Logo quando começou a represa da Itaipu que nossos parentes passaram pro Paraguai. [...] os brancos ainda corriam atrás deles. [...] Eles mandavam embora e se não queria ir eles mandavam na marra mesmo, espancavam...eles nem colocavam caminhão pros índios ir, tinha que ir de a pé mesmo...a minha sorte é que eu não estava ali quando começou isso... (MARTINEZ, 2014).

João Centurião, vivenciou todo esse processo de expropriação territorial, desde Colônia Guarani (Tekoha que ficava no município de Foz do Iguaçu) ao Ocoy Jacutinga. Recorda da existência de várias aldeias, inclusive de uma denominada Takua Pinda'i e do estupro e assassinato de uma menina Guarani: "Um branco entrou e pegou a menina do homem e levou pro mato assim e depois o pai dela levou pra ver o mundéu. E daí que matou no mato também" (CENTURIÃO, 2013). Este depoimento pode ser somado ao coletado por Albernaz (2009, p. 123-125) na qual aparece o relato de assassinato de uma liderança indígena da Aldeia Tekoha Guasu de Jacutinga identificada como Maximino.

Honório Benites, recorda de uma aldeia, denominada São João, que havia na região de Sete Quedas, município de Guaíra, da qual os Guarani foram expulsos pela Itaipu:

E naquela volta, nas Sete Quedas, aquela volta ficou embaixo d'água (...) cobriu aquele pedaço ali, metade pegou água e metade ficou pra fora. Depois os índios saíram tudo, uns foram pro Mato Grosso, outros não sei pra onde, se extraviaram. O pessoal de lá de Jacutinga, um foi pro Paraguai, um foi pro centro, tem alguns que foi pra São Paulo... (BENITEZ, 2013).

Nabor Martines e sua esposa Marta Martins fugiram para o Mato Grosso do Sul pelo medo de Itaipu (MARTINES, 2013).

Além da memória Guarani sobre o sarambi e as violências cometidas pelos órgãos oficiais, localizamos documentos que corroboram com as narrativas orais. Em 1975 e 1976, o presidente do Diretório Municipal do Movimento Democrático Brasileiro (MDB) de Foz do Iguaçu, Antônio Vanderlei Moreira, denunciou a queima das casas Guarani pelo Incra. Os documentos foram encaminhados ao Deputado Estadual e correligionário Fidelcino Tolentino, ao Ministro da Justiça Armando Falcão e ao Delegado da $4^{\text {a }}$ Delegacia Regional da Funai em Curitiba. 
O Incra se defendeu acusando o indígena Nicolau Fernandes de vender "lotes e pequenos roçados" dentro da área do projeto, sem o consentimento do órgão fundiário, e que já teria "fixado muitos aventureiros", também desqualifica os Guarani (chamando-os de “mestiços”) que estariam atuando em contrariedade este órgão (INCRA, 1976).

Apenas em 1976, a Funai inicia tratativa relativa a averiguar a presença de indígenas que sofreriam impactos com o alagamento de suas terras através do Oficio $n^{\circ}$ 045/76-Gab/4 ${ }^{\mathrm{a}}$ DR do delegado regional ao presidente da Funai. No mês de maio desse mesmo ano o Delegado Regional da Funai repassou informações ao presidente do órgão segundo as quais "as terras ocupadas por famílias indígenas na região do Ocoy serão totalmente inundadas por efeito da instalação da hidrelétrica de Itaipu", pede que as famílias sejam removidas do Projeto Integrado de Colonização (PIC-OCOI) e reassentadas em local próximo a represa a ser construída; No mês seguinte, o presidente da Funai Ismarth de Araújo enviou ofício ao presidente do Incra dizendo que os Guarani que habitam Ocoy estão sendo ameaçadas de despejo sumário por técnicos do Incra. Pede ao órgão manifestar-se com relação a uma solução para os Guarani da região (tanto Ocoy como de Colônia Guarani) em face a discordância do IBDF assentá-los no PNI. No início do ano seguinte o presidente da Funai Ismarth de Araújo baixou a Portaria no 162 (relativo ao Processo FUNAI/BSB/0.053/76) criando o Grupo de Trabalho - composto por Saul Carvalho Lopes (Funai), Waldir de Oliveiras Medeiros (Incra) substituído por Wilson Luiz Kaniak (Incra) ${ }^{7}$ - para averiguar a situação dos Guarani em "Três Lagoas e Projeto Ocoí”. Ao analisar o relatório do GT constata-se: 1) A exiguidade de prazo para conclusão do trabalho: 20 dias; 2) Não contou com nenhum antropólogo ou profissional da área de ciências humanas; 3) O trabalho de campo teria durado apenas dois dias; 4) Os Guarani não foram ouvidos - as informações colhidas foram diretamente repassadas pelos técnicos do Incra ao GT. Brant de Carvalho (2005, p.56) argumenta que os trabalhos técnicos demonstram que a Funai agiu a reboque do Incra, pois na “prática o GT recebe de antemão a definição de quem seria índio ou não, dos próprios técnicos do INCRA, órgão que, como vimos, estava implicado contra interesses indígenas na região". O GT identificou 5 (cinco) medidas a serem adotadas, dentre elas destinação de lotes individuais para as 11 famílias, num total de 330 ha, cabendo 30 ha por famílias.

A partir da leitura da atuação dos órgãos estatais envolvidos neste GT (Incra e Funai) pode-se concluir que havia uma estratégia claramente articulada para expulsar os indígenas de

\footnotetext{
7 Saul Carvalho Lopes (Coordenador de área do Departamento Geral de Operações da Funai), Waldir de Oliveiras Medeiros (engenheiro agrônomo Incra) posteriormente substituído por Wilson Luiz Kaniak (advogado do Projeto Fundiário do Paraná.
} 
suas terras tendo em vista que uma área já reconhecidamente indígena teve instalado um projeto de colonização pelo Incra que, para tal, contou com apoio da Funai (PIC-OCOI I e PIC-OCOI II) através de certidão negativa de presença indígena. Para a Funai, no PIC-OCOI I não havia "qualquer resquício de elementos indígenas" e, no PIC-OCOI II, existiam apenas 11 famílias guarani “em processo de aculturação", segundo a Funai.

A Funai propôs a solução camponesa para os Guarani, retirando deles a condição de coletividade e, portanto, de grupo étnico e emprega a propriedade privada como solução. A partir dessa determinação toda a solução proposta, decorrente da mesma, agrava a violação dos direitos Guarani. Ismarth de Araújo, presidente da Funai, formaliza a proposta à Itaipu no sentido de assentar as 11 famílias indígenas, num total de 27 pessoas, na margem do lago, tal qual sugeriu o GT Incra-Funai (BRASIL/FUNAI, OFICIO Nº 285/PRES DE 01.06.1977)

O que os órgãos não esperavam era a reação dos Guarani questionando tal decisão. Para isso contaram com apoio decisivo do Conselho Indigenista Missionário (Cimi), Comissão Justiça e Paz (CJP) e Associação Nacional de Apoio ao Índio (Anai) - as duas últimas de Curitiba. Estas entidades: 1) Demonstraram as irregularidades e ilegalidades cometidas pelo GT Incra-Funai; 2) Colaboraram para que os Guarani compreendessem seus direitos passando a reivindicar $1.500 \mathrm{ha}^{8}$; 3) Também insistiam que a Funai, Incra e Itaipu deveriam buscar áreas maiores no Paraná para assentar a população; 4) Associado a esses aspectos, buscaram localizar os Guarani que haviam cruzado o rio Paraná fugindo da violência. Os órgãos públicos temeram esse novo contexto porque poderia atrapalhar os encaminhamentos que estavam sendo tomados à revelia da legislação. Para Itaipu, o receio maior era atrasar o fechamento das comportas. Notícias dos Guarani começaram a circular nos principais jornais de circulação nacional.

Porém, havia um agravante, o barramento da hidrelétrica estava quase pronto, não restava muito tempo para encontrar uma solução, e em regime de exceção de direitos os canais democráticos estavam interrompidos. Apesar do contexto, os Guarani Fazem uso dos meios de comunicação para denunciar a Itaipu e Funai; produzem documentos denunciando as violações; as lideranças se deslocam para a capital do estado e capital federal para fazer tratativas diretamente com as chefias da Funai e Itaipu. A Funai se sentido acuada, buscou respaldo antropológico para justificar sua atitude. Em meados de 1981 a Assessoria Geral de estudos e Pesquisas (AGESP) da Funai “enviou o funcionário Célio Horst, de péssima fama

\footnotetext{
${ }^{8} \mathrm{O}$ tamanho de 1500 ha proposta pelas entidades da sociedade civil com respaldo dos Guarani foi a partir do último local ocupado pelos Guarani, a área compreendida entre os rios Ocoy e Jacutinga, a estrada de Santa Helena e o Rio Paraná.
} 
entre os povos indígenas do Brasil” (BOLETIM LUTA INDÍGENA, 1981, p.6). De acordo com o relatório do CTI este funcionário aplicou os "critérios de indianidade" (CTI, 2013).

Em um dia de visita à área Horst produziu um laudo concluindo que, das onze famílias Guarani somente cinco seriam indígenas e sugere que para estas sejam destinados lotes individuais (reforçando a tese da "solução camponesa") sendo posteriormente desapropriados e transferidos para a T.I. Rio das Cobras (a prática de transferência era comum na Funai, apesar de sua ilegalidade). Para o Estado não era suficiente expulsar os Guarani de suas terras, era essencial negar sua identidade indígena para impedir, inclusive, reinvindicações futuras. Respaldado pelo relatório de Horst, o Incra expediu cinco títulos de propriedade privada (22ha cada) para as famílias Guarani (BRASIL/FUNAI, Of. No 260/81). O presidente da Funai (em exercício) Octavio Ferreira Lima enviou ofício ao gen. Cosa Cavalcanti (pres. da Itaipu) informando-lhe da conclusão dos "estudos antropológicos de identificação e caracterização dos índios" bem como informando que a solução seria a transferência "para área sob jurisdição" da Funai, na T.I. Rio das Cobras (BRASIL/Funai, OFÍCIO No 357/PRES BSB 10/09/1981). Em março de 1981, líderes Guarani foram até a $4^{\text {a }}$ DR da Funai em Curitiba, "exigir do Delegado que a lei se cumpra e dizer que os Guarani querem uma terra de mato, onde sua comunidade possa viver no seu sistema. Rejeitaram a proposta do delegado Harry Telles de ir para uma reserva" (LUTA INDÍGENA, $\mathrm{n}^{\circ}$ 16, 1982, p.6); rejeitavam qualquer tentativa da Funai transferi-los para a terra do povo Kaingang, distante $300 \mathrm{~km}$. Sem uma resposta afirmativa, os Guarani se deslocaram à capital Federal em dezembro de 1981 e entregaram um documento ao presidente da Funai exigindo uma área de no mínimo 1.500 ha na região oeste do Paraná e "com mata". Indicaram como uma das possibilidades o Parque Nacional do Iguaçu, uma reserva federal criada em 1939 com 180 mil hectares.

Afim de se contrapor ao laudo "antropológico" de Célio Horst, as organizações indigenistas (Cimi e Comissão Justiça e Paz) solicitaram a Associação Brasileira de Antropologia (ABA) um contra laudo, a fim de contestar os critérios de indianidade utilizados. A peça técnica é produzida pelo antropológico de Edgar de Assis Carvalho em 1982. O Laudo produziu efetivos positivos, porém a obra do barramento da represa andava a passos largos, em pouco tempo o rio seria fechado. Pressionados pelo fechamento das comportas os Guarani aceitam a oferta da Itaipu, e o acordo foi celebrado em 12 de maio de 1985. O Incra expediu títulos individuais a 19 famílias Guarani, como se camponeses fossem,

\footnotetext{
${ }^{9} \mathrm{O}$ laudo de Horst foi contestado à época por outro laudo produzido pela antropóloga da própria FUNAI, Rosane Cossich Furtado, e por outro produzido pelo antropólogo designado pela Associação Brasileira de Antropologia a pedido do Cimi Sul e da ANAI (PR), Edgard de Assis Carvalho, mas foram sumariamente ignorados, prevalecendo o de Horst.
} 
imediatamente a Itaipu os desapropriou e com os recursos foi adquirida uma nova terra. Em agosto de 1982 a terra foi registrada no cartório com 231,88 ha, na seguinte composição: (177,5601 ha. “cedidas” pelo Incra e 54,3199 ha. pela Itaipu). Como demonstram os estudos feitos por Brant de Carvalho, o conjunto de terras está “superposto (...) à APP de Itaipu. Assim, desde o início, a área adquirida, aparentemente para os indígenas, já tinha dupla finalidade, superposta, de APP e TI.”, isto é, a Itaipu não destinou terras aos Guarani, pelo contrário, instalou-os em área sujeita à inundação e de preservação ambiental, em situação de risco ambiental e sanitário como demonstraram epidemias de malária e desbarrancamento da terra na margem do lago.

Antes de fechar o acordo que cederia terras da APP do lago Itaipu aos Guarani o advogado indigenista Carlos Frederico Marés de Souza Filho, finalizou o laudo jurídico "Sobre a forma de transmissão da propriedade e posse aos índios Ava-Guarani do rio Ocoy na nova área a lhes ser destinada" demonstrando que toda a ação foi ilegal e que a nova área também seria ilegal.

Em outubro de 1982 a Itaipu fechou as comportas e inundou o Paraná rembe.

\section{Conclusões}

Os guarani conseguiram descontruir o discurso oficial da sua não existência na região e do direito que tinham sobre as terras que ocupavam. Apesar da terra conquistada (atual Ocoy) ser pequena e imprópria, ela serviu para que as famílias dispersas pelo sarambi, pudessem se reencontrar novamente na região. Entendiam os Guarani que esse local seria provisório. Se organizaram coletivamente, e iniciaram um processo de cobrança da dívida da Itaipu, Funai e Incra. Os Guarani pediam ao menos 1500 ha, tamanho do Tekoha Ocoy Jacutinga, nas margens do rio Paraná.

A Funai se manifestou contestando a afirmação de que os Guarani ocupavam área equivalente a 1500 ha:

Repete-se que a assertiva induz, de soslaio, ao entendimento de que os índios AvaGuarani foram deslocados de uma área de 1500 hectares para uma bem menos, de pouco mais de 250 hectares (...). Ao contrário, as provas existem que os índios AvaGuarani (...) em verdade viviam em uma pequena porção de 100 hectares e não contavam mais que 70 indivíduos.” (BRASIL/FUNAI, Processo $\left.n^{\circ} 1573,1990\right)$.

No contexto da reorganização interna e na ação da comunidade pela garantia do direito efetivo à terra, alguns fatos demonstram que o sistema de repressão do período da Ditadura Militar continuaram sendo praticados, como a perseguição a indígena e seus aliados. Além da 
espionagem da Assessoria da Segurança e Informação da Funai (ASI/Funai), tanto os Guarani sofreram ameaças como seus apoiadores. Em de 20/11/86 foi lavrado em cartório uma denúncia de amaças sofridas pelos Guarani por recusar a instalação do Posto Indígena da Funai no interiori da nova terra. A Funai fez uso do Líder Kaingang de Guarapuava Pedro Cornélio Seg Seg, que dias antes esteve na região e tentou convencer os Guarani de desistir de reivindicar mais terras e de aceitar o Posto Indígenas. Para o Cimi Sul a ação era organizada pelo Administrador da Funai em Curitiba Edívio Battistelli.

No dia 02-07-1990 a Polícia Federal inquiriu o bispo da diocese de Foz do Iguaçu Dom Olívio Aurélio Fazza querendo informações do mesmo sobre o trabalho do Cimi junto aos Guarani no Ocoy, especialmente relacionado ao aspecto fundiário. No dia 10 do mesmo mês dois agentes da PF dirigem-se a casa da equipe do Cimi em São Miguel do Iguaçu e interrogam a membro da equipe. Ocorre que não apresentaram nenhum mandato ou mencionaram a abertura de Inquérito, demonstrando que tratava-se de ação semelhante as que ocorriam no período militar.

No dia 25 de abril de 1990, Maria Inês Minatel, membra do Cimi que atua com os Guarani do Ocoy, registra queixa crime na Delegacia de Polícia Civil de São Miguel do Iguaçu, contra o Engenheiro Agrônomo da Itaipu Binacional, Klauss Grainer, que a teria ameaçado exigindo que o Cimi parasse de apoiar a reivindicação de terras pelos Guarani. A Binacional não reconhecia que os Guarani tinham direito a mais terras.

Os Guarani continuam insistindo na devolução das terras. Em 1995, cansados de esperar uma posição de Itaipu, decidem ocupar o refúgio Biológico Bela Vista, terra pertencente a Binacional, que o denominam de Paraná Porã. A ocupação agiliza o processo de aquisição de 1.700 hectares de terra no município de Diamante D’Oeste (PR), constituído o atual Tekoha Añetete. Porém, novos estudos documentais e a memória Guarani, registrada por diversos pesquisadores, demonstraram que os Guarani não ocupavam apenas os 1500 ha no Ocoy/Jacutinga, mas pelo menos 19 outras terras que ficaram submersas, apenas na margem esquerda do rio Paraná. Essa constatação aliada ao aumento populacional gestou um novo cenário regional, os Guarani retomaram pelo menos vinte e uma novas terras. No momento atual 14 Tekoha estão com os estudos de identificação e delimitação concluídos e outros 07 estão em processo de estudos.

\section{Referências}


ALMEIDA, M. R. C. Os índios na história do Brasil. Rio de Janeiro: FGV, 2010. (Obra Completa)

ALVES, P. Depoimento ao Centro de Trabalho Indigenista. Tekoha Ocoy, 2013. (Entrevista).

BOGADO, A. Depoimento a Eleine Pereira Rocha. Tekoha Ocoy, 1990. (Entrevista).

BENITEZ, H. Depoimento ao Centro de Trabalho Indigenista. Santa Helena, 2013. (Entrevista).

BRANT DE CARVALHO, M. L. "O processo de desterramento da população indígena AváGuarani da imemorial terra de ocupação tradicional denominada Ocoy-Jacutinga e o reassentamento na atual Terra Indígena Avá-Guarani do Oco’y/ São Miguel do Iguaçu/Pr: Aspectos antropológicos e jurídicos. Pericia Antropológica, 2004. (Laudo técnico antropológico).

BRANT DE CARVALHO, M L. O processo de desterramento da população indígena AváGuarani da imemorial terra de ocupação tradicional denominada Oco'y-Jacutinga e o reassentamento na atual Terra Indígena Avá-Guarani do Oco’y/ São Miguel do Iguaçu/Pr: Aspectos antropológicos e jurídicos. Pericia Antropológica, (2 parte) 2005. (Laudo técnico antropológico).

BRANT DE CARVALHO, M. L. Das terras dos índios aos índios sem terras o Estado e os Guarani do Oco`y, silêncio e luta. Tese. DPG em Geografia Humana. FFLCH/USP 2013. (Tese).

BRASIL/FUNAI, Oficio $n^{o}$ 285/PRES de 01.06.1977 do presidente da FUNAI General Ismarth de Araújo ao General José Costa Cavalcanti, diretor da Itaipu Binacional. Brasilia, DF, 1977. (Documento).

BRASIL/FUNAI, Of. $N^{o}$ 260/81/4 DR de 19 de junho de 1981, do Delegado regional da FUNAI Harry Luiz Ávila Teles ao coordenador regional do INCRA José Guilherme Lobo Cavagnari. Brasília, DF, 1977. (Documento).

BRASIL/FUNAI, Ofício $N^{o}$ 357/PRES BSB 10/09/1981 do Presidente da FUNAI Octavio Ferreira Lima ao Diretor Geral de Itaipu Binacional Gen. José Costa Cavalcanti. Brasilia, DF, 1981. (Documento).

BRASIL/FUNAI. Oficio $n^{o}$ 129/76-Gab/4a DR 26.05.76. Brasília, 1976. (Documento).

BRASIL, Justiça Federal. Processo $n^{\circ} 1573$, livro 01, folha 88. Em 22.10-1990. Folhas 258 e 259. Nesse documento aparece um registro da documentação: Proc. FUNAI/BSB/1053/76. (Documento).

BOLETIM LUTA INDÍGENA. Conselho Indigenista Missionário. Xanxerê, 198. (Periódico).

CARNEIRO DA CUNHA, M. (Org). História dos Índios no Brasil. São Paulo: Cia da Letra e Secretaria. Municipal da cultura, Fapespe, 1992. (Obra completa).

CATU DE ALMEIDA, N. Entrevista Concedida Maria Lucia Brant De Carvalho. Tekoha Ocoy, 2005. (Entrevista). 
CENTURIÃO, J. Depoimento ao Centro de Trabalho Indigenista. Tekoha Ocoy. 2013. (Entrevista).

CENTURIÃO, J. Depoimento a Eleine Pereira Rocha. Tekoha Ocoy 1990. (Entrevista).

CTI. Violações dos direitos humanos e territoriais dos Guarani no Oeste do Paraná (19461988): Subsídios para a Comissão Nacional da Verdade. São Paulo, 2013. (Laudo técnico histórico).

EREMITES, G. Sobre os conceitos de Etnoistória e História Indígena: uma discussão ainda necessária. XXII Simpósio Nacional de História - João Pessoa, 2003. (Anais de evento científico).

INCRA/OF/INCRA. Oficio 4 (09) $N^{o}$ 1729/76. 24.05.76 de Aroldo José Moletta, Coordenador Regional do Incra, ao Francisco Neves Brasileiro, Delegado Regional da Funai). Brasília, 1976. (Documento).

MARTINES, N. Depoimento ao Centro de Trabalho Indigenista. Tekoha Ocoy. 2013. (Entrevista).

MARTINEZ, D. Depoimento ao Centro de Trabalho Indigenista. Tekoha Ocoy. 2014. (Entrevista).

MAZZAROLlO, J. A taipa da Injustiça: Esbanjamento econômico, drama social e holocausto ecológico em Itaipu. São Paulo: Loyola, 2003. (Obra completa).

PORTELli, A. O que faz a História Oral diferente. Projeto História, São Paulo, n.14, fev 1997, p.25-39. (Artigo de revista científica)

REZENDE, J. Entrevista Concedida a Clovis Antonio Brighenti. Brasílias, 2015. (Entrevista).

ROCHA, E. P. Ava Guarani: Presente. Laudo histórico sobre os Guarani no Ocoy. Xanxerê, 1991. (Laudo técnico histórico).

SOAVINSKI, Carla. Terra pela qual se luta, terra na qual se vive: o refazer da vida e da terra dos Avá-Guarani do Oeste do Paraná após o desterro. Dissertação apresentada ao Programa de Pós-Graduação em Antropologia Social do Departamento de Antropologia da Universidade de Brasília. Brasília: UNB. 2019. (Dissertação).

VAINFAS, R. Trópicos dos pecados: moral, sexualidade e inquisição no Brasil. Rio de Janeiro: Civilização Brasileira, 2010. (Obra completa).

WACHOWICZ, R. C. Obrageros, Mensus e Colonos. 2. ed. Curitiba: Editora Vicentina, 1987. 218 p. (Obra completa). 